\title{
Estudo de caso de dois acidentes do trabalho investigados com o método de árvore de causas
}

\section{Case report of two work accidents investigated using the causal tree method}

Maria Cecília Pereira Binder 1

Ildeberto Muniz de Almeida 1

1 Departamento de Saúde Pública, Faculdade de Medicina de Botucatu, Universidade Estadual Paulista.

Campus de Botucatu Rubião Jr., Botucatu, SP 18618-000, Brasil.
A bstract In a large company in São Paulo State, two work accidents were investigated using the Causal Tree Method (CTM), leading to the accurate identification of factors related to work organization as the causal factors for the accidents. These cases pointed to the role of organizational factors, such as improvised and temporary assignments to work stations and/or jobs, decisions about the performance of tasks left to unprepared workers, unavailability of proper tools and/or materials, and faulty information distribution within the company. Analysis of the accidents allowed for the presentation and discussion of the method (CTM), its lengthy application, its demands in terms of training, and its potentialities for accident prevention.

Key words Worker' Health; Occupational Accidents; Causal Tree Method

Resumo São apresentados dois acidentes do trabal ho típicos, ocorridos em empresa de grande porte, investi gados com o Método de Árvore de Causas - ADC, método que permi te identificar o papel desempenhado por fatores gerenciais e de organização do trabal ho no desencadeamento desses fenômenos. Os casos apresentados revelam a parti ci pação, na gênese dos aci dentes, de fatores como desi gnação temporária e improvisada de trabalhadores para funções e postos de trabalho, execução de tarefas deixadas à ini ciativa e ao arbítrio dos trabal hadores, falta de ferramentas e de materiais apropriados à execução de tarefas efal has na circulação de informações, entre outros. São também anali sadas as indicações para o uso do método, suas potencialidades em termos de prevenção, bem como as implicações decorrentes de dificuldades de aplicação, de necessidades de treinamento e reciclagens e do dispên di o el evado de tempo para investi gação de cada acidente.

Palavras-chave Saúde do Trabalhador; Acidentes do Trabalho; Método de Árvore de Causas 


\section{Introdução}

Na década de 80 (1981 a 1990), foram registrados junto à Previdência Social 10.374.247 acidentes do trabalho (AT), dos quais 254.550 resultaram em invalidez e 47.251, em óbito (IBGE, 1981; 1982; 1983; 1984; 1985; 1986; 1987; 1988; 1989; 1990), valores que apontam para a necessidade de, entre outras, priorizar as ações de preven ção desses fenômenos pelas instituições que se ocupam da saúde do trabalhador. Em que pese a precariedade das informações epidemiológicas disponíveis (Alves \& Luchesi, 1992; Hirata \& Salerno, 1995), os acidentes do trabalho ainda constituem importante problema de saúde pública em nosso país.

Dada a gravidade do problema, assume grande importância a detecção a priori de riscos, isto é, antes que os acidentes aconteçam. Há vários métodos desenvolvidos com esta finalidade, cabendo ressaltar que, para sistemas de menor complexidade, o método de escolha é constituído pelas inspeções de ambientes e de condições de trabalho (Monteau \& Favaro, 1990b; Monteau, 1992), capazes de identificar perigos decorrentes, entre outros, de problemas de segurança de máquinas, postos de trabalho, lay-out, limpeza, ambiente físico, presentes - e visíveis - de maneira permanente nos ambientes de trabalho.

Por outro lado, se há al guns fatores da organização do trabal ho e gerenciais identificáveis à inspeção, como ritmo intenso, trabalho em turnos e noturno, seqüência irracional de operações, existem vários outros que dificilmente são evidenciados por inspeções, por ocorrerem de forma eventual e limitada no tempo, como, por exemplo, designação improvisada de trabalhadores para execução de tarefas, uso de materiais por várias equipes sem designação de responsável, falta de ferramentas e materiais necessários à execução de tarefas eventuais ou não rotineiras. Tais fatores, à medida em que os problemas mais críticos de insegurança vão sendo superados, adquirem importância crescente no desencadeamento de acidentes (Monteau \& Pham, 1987; Monteau, 1992), situação em que a investigação a posteriori dos acidentes com o Método de Árvore de Causas - ADC está indicada, dada a capacidade desse método para evidenciá-los (Monteau, 1980).

No Brasil, grande parte das investigações de acidentes, realizadas por força de normas legais pela maioria das empresas, ainda baseiase na concepção dicotômica de ato inseguro e de condições inseguras, freqüentemente desembocando na atribuição de culpa ao traba-
Ihador pelo evento que o vitimou e recomendando medidas de prevenção orientadas para mudanças de comportamento, sabidamente as mais frágeis (Binder et al., 1994).

Em contradição com essa realidade, a partir de abril de 1994, tem havido iniciativas do Ministério do Trabalho no sentido de tornar obrigatória a investigação de todo e qual quer acidente do trabalho com o M étodo de Árvore de Causas, sem considerar: 1) os aspectos técnicos do método, 2) a heterogeneidade quanto ao grau de segurança das empresas brasileiras e 3) a necessidade de capacitação de grande número de profissionais para aplicação minimamente adequada do mesmo - para mencionar apenas os três problemas que reputamos mais relevantes e que, não sendo devidamente equacionados, poderão comprometer os resultados de tais iniciativas. Nesse sentido, cabe mencionar que os autores dos primeiros estudos de caso com o método ADC, divulgados entre nós, abandonaram alguns de seus princípios e regras (Lara Duca, 1987; Magrini, 1989; Ferrão, 1996).

A presente comunicação discute a aplicação do Método de Árvore de Causas (Cuny \& Krawsky, 1970; Monteau, 1980; Monteau, 1983) com base em duas investigações de acidentes do trabalho típicos, enfocando aspectos como: a) o caráter pedagógico do método, que facilita a compreensão de fenômenos complexos e pluricausais como são os acidentes de trabaIho; b) sua capacidade de identificar aspectos da organização do trabalho e gerenciais envolvidos na origem de acidentes, dificilmente evidenciados por outros métodos; c) suas potencialidades em termos de prevenção de novos acidentes, partindo da identificação e eliminação ou neutralização dos fatores envolvidos na ocorrência do acidente analisado; d) a não-exigência de conhecimento a priori de processos de produção e de trabalho (condição desejável mas não imprescindível); e) as necessidades de treinamento e de reciclagens, bem como o elevado consumo de tempo requeridos para sua adequada aplicação e, finalmente, f) suas possíveis contribuições para a superação da prática de atribuição de culpa ao acidentado pelo acidente que o vitimou.

\section{O método de árvore de causas - ADC}

Trata-se de método baseado na Teoria de Sistemas, o qual aborda o acidente de trabal ho como fenômeno complexo, pluricausal e revelador de disfunção na empresa, considerada como um sistema sócio-técnico aberto. Sua apli- 
cação exige reconstrução detalhada e com a maior precisão possível da história do acidente, registrando-se apenas fatos, também denominados fatores de acidente, sem emissão de juízos de valor e sem interpretações, para, retrospectivamente, a partir da lesão sofrida pelo acidentado, identificar a rede de fatores que culminou no AT (Cuny \& Krawsky, 1970; Monteau, 1980; Monteau, 1983).

O método utiliza o conceito de variação, entendida como mudança ocorrida em relação ao funcionamento habitual do sistema (indústria, oficina etc.), considerada indispensável à ocorrência do acidente. Utiliza também o conceito de atividade, constituída de quatro componentes: indivíduo (I), considerado em seus aspectos físicos e psico-fisiológicos; tarefa ( $T$ ), entendida como a seqüência de operações executadas pelo indivíduo e passível de observação; material (M), representado por máquinas, instrumentos, ferramentas, matérias-primas e insumos necessários ao desenvolvimento do trabalho; meio de trabalho (MT), entendido em seus aspectos físi cos e em suas relações sociais.

Identificados os fatores de acidente - variações e fatos habituais - do modo mais exaustivo possível, a construção da árvore não é senão o estabelecimento das ligações lógi cas existentes entre esses, realizado retroativamente a partir da lesão. Esse processo permite ampliar consideravelmente os conhecimentos a respeito dos fatores que participaram da ocorrência do acidente, pois obriga a pesquisa 'das causas das causas', interrompida quando certos fatos, cronologicamente muito anteriores à lesão, foram esquecidos ou quando o investigador avalia que já dispõe de quadro suficientemente coerente e completo do acidente.

Valendo-se dos fatos ou fatores de acidentes específicos e pontuais que compõem a árvore, é possível identificar fatores mais gerais, denominados fatores potenciais de acidentes FPA, cuja presença, como o próprio nome indica, aumenta o risco de ocorrência desses fenômenos (Darmon et al., 1975; Faverge, 1977; INRS, 1976; Monteau, 1974). Além disso, por constituírem formulação mais geral, elaborada com base nos fatores de acidente, apresentam a característica de serem passíveis de identificação em numerosas situações de trabal ho que não exatamente aquelas a partir das quais foram elaborados. Sua eliminação ou neutralização contribui para a prevenção de novos acidentes, semelhantes ou não ao investigado.

Alguns fatores potenciais de acidentes já foram descritos e analisados, podendo ser citados, entre outros, co-atividade, interferência entre tarefas, má circulação de informação na empresa, utilização de materiais por várias equipes sem definição de responsável, incompatibilidade entre materiais de 'gerações' ou idades diferentes, utilização de materiais inadequados ao trabalho em desenvolvimento (fator denominado catacrese por seus autores) e resquícios de atividade anterior (Darmon et al., 1975; INRS, 1976; Faverge, 1977; Monteau, 1974).

\section{Material e métodos}

Com o método ADC (Cuny \& Krawsky, 1970; Monteau, 1980; Monteau, 1983, Binder et al., 1995), são analisados dois acidentes do trabaIho típicos, ocorridos em empresa de grande porte do Estado de São Paulo.

Ambos acidentes foram investigados pelos autores, em atividade de vigilância sanitária de programa de saúde do trabal hador. As investigações foram realizadas no local de ocorrência, entrevistando-se o acidentado, colegas de trabalho, chefe imediato e profissionais de segurança do trabalho da empresa. A coleta de informações foi realizada obedecendo às normas do método ADC.

Foram realizados esquemas e fotografias dos materiais, das posições de trabalho e das instalações em que os acidentes ocorreram.

A partir das árvores obtidas, aplicou-se o conceito de fator potencial de acidente (Darmon et al., 1975; INRS, 1976; Faverge, 1977; Monteau, 1974), com elaboração dos respectivos esquemas.

\section{Resultados e discussão}

\section{Caso no 1}

Sr. F., 40 anos, ajudante de limpeza da empresa há 1,5 ano. Sua tarefa, realizada com o auxílio de um colega, consiste na retirada de tambores com resíduos esucata em diversos setores da fábrica, habitualmente executada utilizando-se carreta tracionada por vé́culo motorizado (jeepinho). Quando da ocorrência do acidente, o veículo estava em pane, aguardando conserto, há um mês. Por esta razão, vinha sendo utilizada uma carreta reserva com as seguintes características: 2,40 m de comprimento; $1,20 \mathrm{~m}$ de largura; 0,91 m de altura; quatro rodas com 0,20 m de diâmetro; peso de cerca de 100 kg (vazia) e tração manual. Deixada no pátio, sujeita a intempéries, tal carreta apresentava mau estado de conservação, com diversas equi pes fa- 
zendo uso dela, sem designação de responsável e com manutenção genericamente atribuída aosajudantes de limpeza.

Utilizando diariamente a carreta reserva há um mês, o Sr. F. eseu colega (Sr. Y), na manhã do acidente, iniciaram sua reparação pela troca das laterais. Prevendo que, pela ação da chuva, a carreta poderia deteriorar rapidamente, Sr. F. havia decidido fixar tiras de plástico rígido na facesuperior das laterais, material esse previamente obtido por el eem tambores de lixo e cortado nas dimensões das partes a proteger. Não há prescri ção sobre como executar esse tipo de conserto etampouco provisão de materiais necessários. Não possuindo caixa deferramentas, o Sr. F. apanha um martelo queencontra no lixo na manhã do dia do acidente.

Durante a jornada, iniciada às 7h, o Sr. F. e seu col ega retiram o lixo até por volta de 16h, quando essa tarefa, realizada em duplas, é interrrompida em virtude da ausência não suprida do Sr. Y., que vai ao dentista.

Alegando não gostar de parecer desocupado, Sr. F. retoma sozinho a reparação da carreta pela colocação das tiras de plástico na face superior das laterais. A primeira delas tem dimensões de $240 \mathrm{~cm}$ (comprimento) por 3,5 cm (largura) e $0,3 \mathrm{~cm}$ (espessura). Para fixá-la, usa pregos tamanho $28 \times 24$, reaprovei tados de embalagens (reaproveitamento praticado com freqüência na empresa).

Após colocar a tira de plástico sobre a face superior de uma das bordas laterais, o Sr. F. posi ciona o primei ro prego em uma das extremidades, segurando-o com o pol egar e indicador esquerdos e firmando o plástico com os demais dedos e palma da mão. Ao desferir o gol pe com o martel o para completar a operação, Sr. F. está com o corpo fl eti do e com o rosto próximo ao ponto defixação. Colocado esse primeiro prego, dirige-se à outra extremidade para repetir a operação, com a dificuldadeadicional deter de manter tracionada a tira de plástico com a mão esquerda. Ao ser martelado com força, esse segundo prego entorta, não penetra no plástico eé lançado em direção ao rosto do Sr. F, chocandose com a lente esquerda de seus ócul os de segurança. A armação e a lente quebram-se e o ol ho esquerdo do Sr. F., atingi do por seus fragmentos e pelo prego, sofre perfuração. A lente remanescente (direita) é submeti da a testes que revelam estar fora das especificações em relação à resi stência a impactos.

Trata-se de acidente ocorrido durante realização de atividade eventual de manutenção de equipamento utilizado para execução de tarefa secundária ou anexa, e a Tabela 1 apresenta o rol de fatos contidos na descrição, reelabora- dos sob forma de frases curtas, classificados como variação $(\bigcirc)$ ou fato habitual $(\square)$ e de acordo com o componente da atividade (Indivíduo - I, Tarefa - T, Material - M, Meio deTrabalho - MT).

A árvore de causas do acidente descrito é apresentada na Figura 1, cuja observação revela a complexidade do acidente, fruto da conjugação de numerosos fatores. A árvore é composta por 31 fatos, dos quais $17(54,8 \%)$ são variações e 12 (38,7\%), fatos habituais. Acerca de dois fatos permanecem dúvidas quanto a tratar-se de variação ou fato habitual, o que é representado pela figura de um círculo no interior de um quadrado. Dois fatos listados na Tabela 1, os de número 17 e 18, não se encontram inseridos na árvore, significando que não participaram da ocorrência do acidente.

A leitura da árvore revela que:

- o componente indivíduo contribui com apenas dois fatos, um dos quais é constituído pela lesão;

- o componente tarefa é majoritário, com 13 variações e nenhum fato habitual, resultado esperado visto tratar-se de atividade eventual de manutenção;

- o componente material contribui com dez fatos, dos quais apenas um constitui variação, sobre dois pesam dúvidas e os sete restantes são fatos habituais;

- o componente meio de trabalho contribui com cinco fatos, sendo uma variação e quatro fatos habituais;

- das quatro interrogações existentes na árvore, uma apresenta maior importância: por que um equipamento de uso rotineiro permanece um mês em pane?

- na origem do acidente, à esquerda da árvore, observa-se que todos os fatos ou fatores de acidente foram classificados como pertencentes ao meio de trabal ho e ao material, com predominância de fatos habituais sobre as variações.

A aplicação do método ADC permite evidenciar que condições freqüentemente toleradas em ambientes de trabalho, tais como pane não solucionada de equipamento de uso cotidiano, falta de responsável pela utilização e manutenção de equipamento, inexistência de pequenos materiais necessários à execução de tarefas estão presentes na origem do acidente. Nessas condições, a execução de uma tarefa eventual - o conserto do carrinho -, deixada ao arbítrio do trabalhador e realizada na ausência de auxiliar cuja substituição não foi realizada pela empresa, desembocou no acidente.

Aplicando-se o conceito de fator potencial de acidentes, elaborou-se o esquema apresen- 
O rganização dos fatos ou fatores de acidentes segundo o componente da atividade e seu caráter habitual ou não, referentes ao caso no 1 .

\begin{tabular}{|c|c|c|}
\hline Fator de acidente & Componente & $\square / 0$ \\
\hline 1. O Sr. F. sofre perfuração ocular (olho esquerdo) & I & $\bigcirc$ \\
\hline 2. O Sr. F. não gosta de parecer ocioso & 1 & $\square$ \\
\hline 3. O prego e fragmentos da lente atingem o olho esquerdo do Sr. F. & $\mathrm{T}$ & ○ \\
\hline 4. A lente esquerda dos óculos de segurança quebra com o impacto & $\mathrm{T}$ & O \\
\hline 5. 0 prego atinge a lente esquerda dos óculos (EPI) do Sr. F. & $\mathrm{T}$ & O \\
\hline 6. 0 prego é projetado em direção ao rosto do Sr. F. & $\mathrm{T}$ & 0 \\
\hline 7. 0 rosto do Sr. F. está perto do ponto de fixação do prego & $\mathrm{T}$ & ○ \\
\hline 8. 0 prego não perfura o plástico & $\mathrm{T}$ & 0 \\
\hline 9. O Sr. F. martela o prego com força & $\mathrm{T}$ & $\bigcirc$ \\
\hline 10. O Sr. F. segura prego e plástico com a mão esquerda & $\mathrm{T}$ & ○ \\
\hline 11. O Sr. F. retoma sozinho a atividade de conserto do carrinho & $\mathrm{T}$ & ○ \\
\hline 12. O Sr. F. fixa uma peça de plástico na borda superior do carrinho & $\mathrm{T}$ & O \\
\hline 13. O Sr. F. está momentaneamente desocupado & $\mathrm{T}$ & ○ \\
\hline 14. O Sr. F. conserta o carrinho reserva & $\mathrm{T}$ & ○ \\
\hline 15. A retirada do lixo é interrompida & $\mathrm{T}$ & $\bigcirc$ \\
\hline 16. O Sr. F. utiliza o carrinho reserva há um mês & $\mathrm{T}$ & O \\
\hline 17. Na véspera do AT, o Sr. F. apanha restos de plástico no lixo & $\mathrm{T}$ & O \\
\hline 18. O Sr. F. corta os plásticos no tamanho das bordas do carrinho & $\mathrm{T}$ & ○ \\
\hline 19. As lentes dos óculos (EPI) do Sr. F. estão fora de especificação & M & $\square$ \\
\hline 20. A borda superior do carrinho está a $0,91 \mathrm{~m}$ de altura & M & $\square$ \\
\hline 21. O martelo está em mau estado & M & $\square$ \\
\hline 22. 0 prego já foi utilizado & M & $\square$ \\
\hline 23.0 prego é grosso & M & $\square$ \\
\hline 24.0 plástico é resistente & M & $\square$ \\
\hline 25. O carrinho reserva está em mau estado & M & $\square$ \\
\hline 26. 0 carrinho reserva é pesado e manual & M & $\square$ \\
\hline 27. O s recipientes de lixo são pesados & M & $\square$ \\
\hline 28. O carrinho motor está em pane há um mês & M & $\bigcirc$ \\
\hline 29. A manutenção do carrinho reserva é tarefa do pessoal da limpeza & MT & $\square$ \\
\hline 30. Não há responsável pelo carrinho reserva & MT & $\square$ \\
\hline 31. O carrinho reserva é usado por várias equipes & MT & $\square$ \\
\hline 32. O carrinho reserva fica estacionado ao ar livre & MT & $\square$ \\
\hline 33. O colega do Sr. F. (Sr. Y.) está no dentista & MT & O \\
\hline
\end{tabular}

O: variação; $\square$ :fato habitual; I: indivíduo; T: tarefa; M: material; MT: meio de trabalho.

tado na Figura 2, que revela a participação decisiva de fatores relativos à organização do trabalho (FPA 1, 2, 3, 5, 6, 7, 8, 10 e 12) no AT investigado.

Alguns dos FPA elaborados a partir desse acidente já estão descritos na literatura (Darmon et al., 1975; Faverge, 1977; Monteau, 1974): utilização de materiais por equipes diferentes sem designação de responsável (FPA 2), pane não solucionada (FPA 5), reparação improvisada (FPA 6) e utilização de materiais impróprios ou catacrese (FPA 10). A análise da árvore e do esquema de fatores potenciais de acidente revela uma situação geral de execução de atividade de manutenção extremamente desfavorável do ponto de vista da segurança do trabalho, na qual todas as decisões, a começar pela de realizar o conserto, foram tomadas por trabalhadores que, além de tecnicamente despreparados, não dispunham dos materiais necessários.

\section{Caso no 2}

Sr. G., 45 anos de idade, admiti do como soldador há cinco anos, na ocasião do aci dente exercia a função de serral heiro, pois, há cerca decinco meses o equi pamento de sol da que operava estava com defeito, aguardando reparação.

Recentemente, coincidindo com novo plano econômi co do governo, a empresa atravessara 
Figura 1

Árvore de causas - caso no 1.

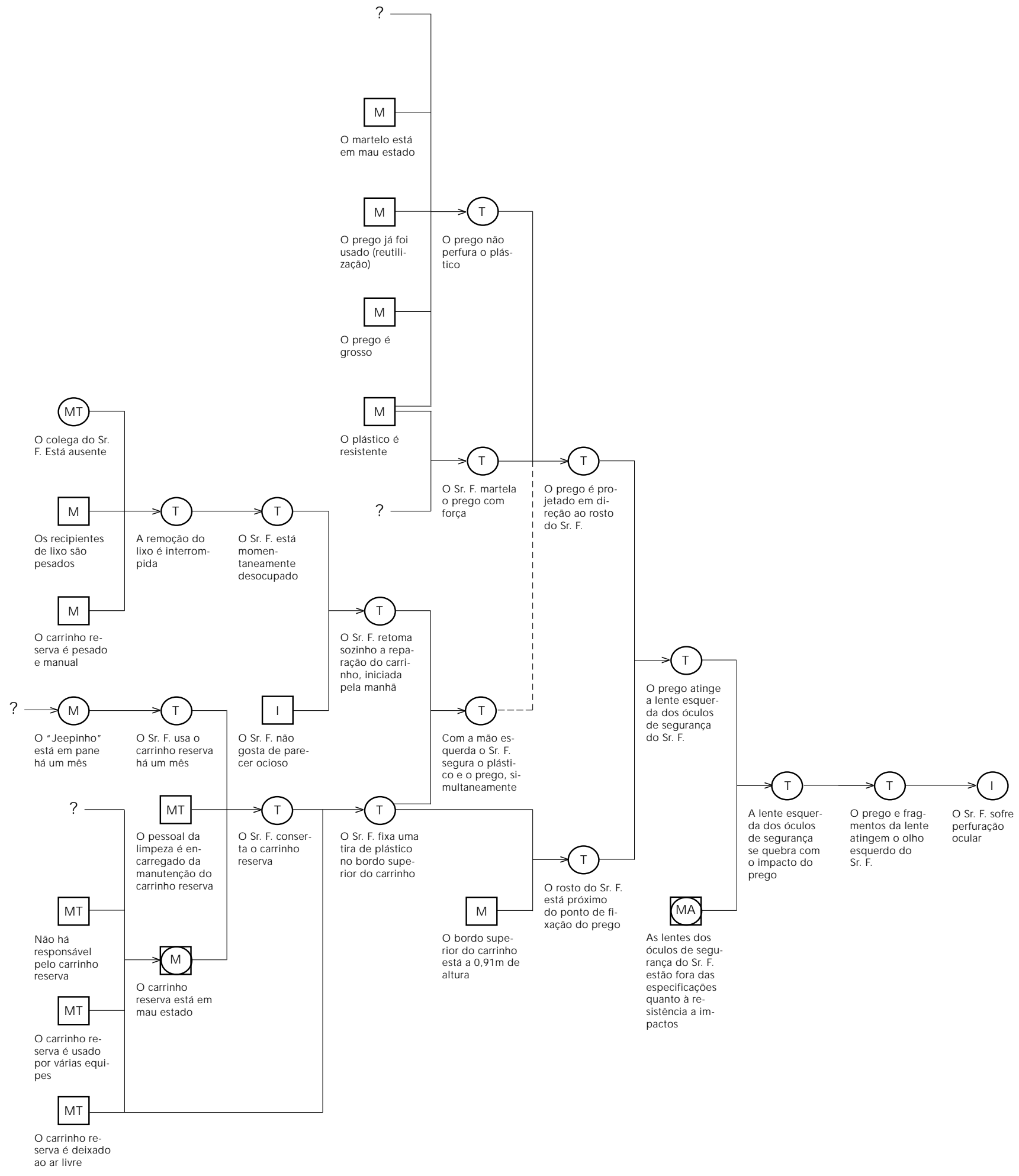

I: indivíduo; T: tarefa; M : material; MT: meio de trabalho. 
fase de dimi nui ção do número de encomendas, dispensando quase duzentos trabalhadores. A posterior retomada do nível de produção não foi acompanhada de recontratações, passando a empresa a aumentar o número de horas-extras ea desl ocar trabalhadores de uma função para outra, de acordo com as necessidades mais prementes e imediatas. Nessa situação, o Sr. G. vinha executando tarefas de serral heiro, sem ter recebi do trei namento nem instruções sobre os riscos desua nova função.

Na manhã da véspera do dia do acidente, o Sr. G. havia sido designado para furar peças que tinham forma aproximada de C, com cantos re tos; espessura de $2,5 \mathrm{~cm}$; altura de $9,0 \mathrm{~cm}$; 'braços do C' com $14 \mathrm{~cm}$ de comprimento e $10,5 \mathrm{~cm}$ de largura. Para tanto, operava uma furadei ra de peças, equipamento fixo, com bancada possuidora de mecanismo para fixação de gabarito, no qual são posi cionadas e presas as peças a serem furadas. Após al gumas horas de uso, esse equipamento, já antigo e não submeti do a manutenções preventivas, quebrou, fato que vinha se repetindo cerca de uma vez por mês, há tempos. O Sr. G. passou a utilizar uma furadeira de chapas para furar as peças. Esta furadeira apresentava como diferenças bási cas em relação à de peças a ausência de mecanismo de fixação de gabarito e bancada com dimensões maiores. $A$ falta desse mecanismo exigia que a furação fosse realizada com o trabal hador segurando manualmente o conjunto gabari to-peça, com peso decerca de $7 \mathrm{~kg}$, sol to sobre a bancada, de modo a mantêlo imóvel ena posição requerida para a realização da tarefa.

No dia seguinte, o Sr. G. dirigiu-se diretamente à furadeira de chapas para dar prosseguimento ao trabal ho iniciado na véspera, supondo quea furadeira de peças ainda não tivesse si do reparada. Na verdade, ela já estava em condições de uso, pois a peça que se quebrara havia sido trocada, fato desconhecido tanto peIo Sr. G., como por seu contramestre.

Com a altura da broca regulada ea rotação ajustada em 400 rpm, o Sr. G. começou seu trabalho. O processo de furação estava sendo realizado em duas etapas: na primeira, com a peça ajustada ao gabarito, eram feitos os dois primeiros furos nos 'braços' horizontais (peça em forma de C), com uma broca fina. Na segunda, com uma broca de 1,3 cm de diâmetro, o furo era ampliado. A primeira etapa já havia sido executada em várias peças e o acidente ocorreu durante a operação de ampliação dos furos da nona peça. Sentado em frente à bancada da furadeira, cuja altura em relação ao solo era de 1,08 m, o Sr. G. mantinha manualmente o conjunto gabarito-peça posicionado e imóvel.
Figura 2

Esquema de fatores potenciais de acidente - caso no 1.

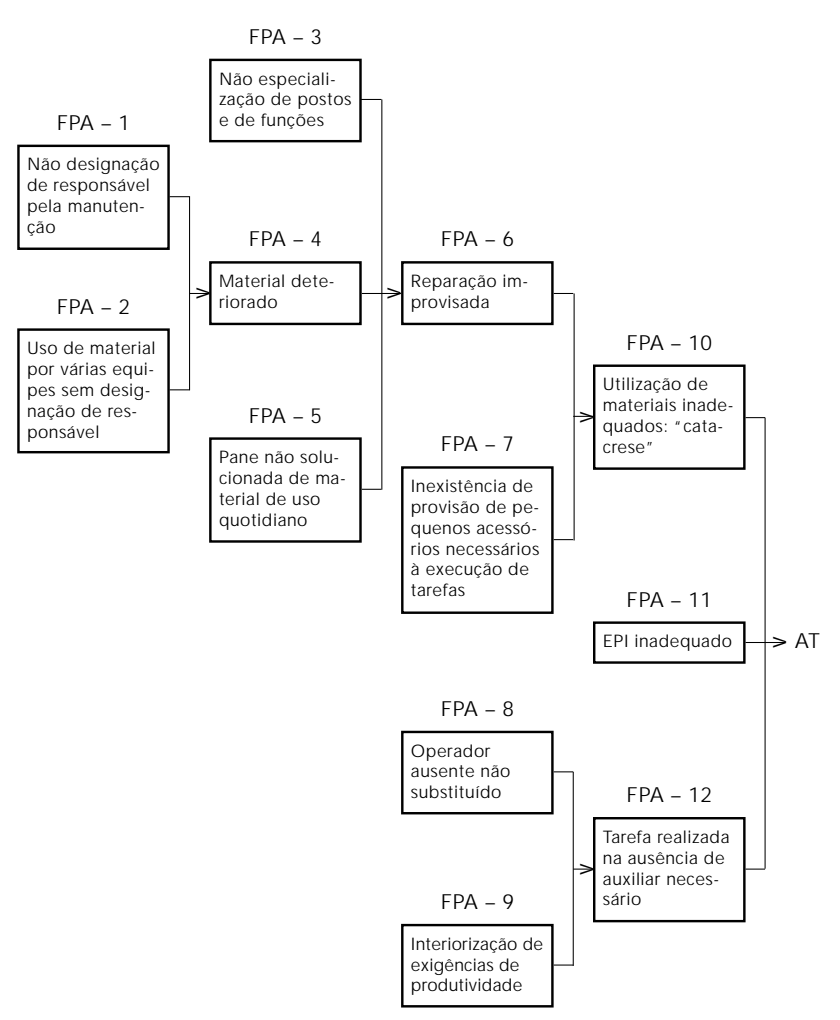

Tendo sido ampliado o furo do 'braço' superior da peça, a broca começou a furar o inferior, atravessando então, os dois 'braços' do C. Nessa situação, o gabarito movimentou-se, travando a máquina, que, destravando-se em seguida, voltou a girar, quebrando a broca e projetando o conjunto gabari to-peça ea broca na direção do trabalhador. Este, sentado na cadeira, de frente para a furadeira, não conseguiu desligar o botão de acionamento - localizado no al to eà esquerda -, não conseguindo também sair a tempo de seu posto de trabalho, sendo atingi do no tórax e sofrendo contusão da parede toráci ca e fratura de duas costelas.

Trata-se de acidente sobrevindo durante execução de tarefa principal de atividade de produção. A Tabela 2 apresenta a relação dos fatos contidos na descrição, reelaborados sob a forma de frases curtas, cada uma delas contendo apenas um fato, classificado como variação (○) ou fato habitual $(\square)$ e de acordo com o componente da atividade (I, T, M, MT). A observação da árvore, apresentada na Figura 3, revela participação de 35 fatos, do quais 15 $(42,9 \%)$ são variações, 12 (31,4\%), fatos habituais e, em relação a nove fatos, persistiram dú- 
Tabela 2

O rganização dos fatos ou fatores de acidentes segundo o componente da atividade e seu caráter habitual ou não, referentes ao caso no 2 .

\begin{tabular}{|c|c|c|}
\hline Fator de acidente & Componente & $\square / 0$ \\
\hline 1. O Sr. G. sofre contusão torácica e fratura duas costelas & 1 & $\bigcirc$ \\
\hline 2. O Sr. G. ignora riscos de furar peças com furadeira de chapas & I & $\square$ \\
\hline 3. O Sr. G. é soldador & 1 & $\square$ \\
\hline 4. O Sr. G. exerce função de serralheiro há cerca de cinco meses & 1 & $\square$ \\
\hline 5. O Sr. G. ignora que a furadeira de peças foi consertada & 1 & $\bigcirc$ \\
\hline 6. O conjunto gabarito-peça atinge o tórax do Sr. G. & $\mathrm{T}$ & ○ \\
\hline 7. O conjunto gabarito-peça é lançado à frente e à direita & $\mathrm{T}$ & ○ \\
\hline 8. O Sr. G. está na frente do conjunto gabarito-peça & $\mathrm{T}$ & $\square$ \\
\hline 9. 0 Sr. G. trabalha sentado na frente da furadeira & $\mathrm{T}$ & $\square$ \\
\hline 10. O conjunto gabarito-peça está solto sobre a bancada & $\mathrm{T}$ & ○ \\
\hline 11. O Sr. G. usa uma furadeira de chapas para furar peças & $\mathrm{T}$ & $\bigcirc$ \\
\hline 12. O Sr. G. fura peças & $\mathrm{T}$ & $\bigcirc$ \\
\hline 13. O conjunto gabarito-peça se movimenta & $\mathrm{T}$ & ○ \\
\hline 14. A broca atravessa os dois braços da peça & $\mathrm{T}$ & $\square$ \\
\hline 15. O Sr. G. mantém conjunto gabarito-peça imóvel manualmente & $\mathrm{T}$ & $\bigcirc$ \\
\hline 16. 0 'braço' superior da peça já está furado & $\mathrm{T}$ & $\square$ \\
\hline 17. O conjunto gabarito-peça pesa cerca de $7 \mathrm{~kg}$. & M & $\square$ \\
\hline 18. A furadeira trava & M & ○ \\
\hline 19. A broca da furadeira quebra & M & $\bigcirc$ \\
\hline 20. A broca da furadeira permite acesso de mãos & M & $\square$ \\
\hline 21. A furadeira de peças entrou em pane na véspera & M & ○ \\
\hline 22. A broca gira a $400 \mathrm{rpm}$. & M & $\square$ \\
\hline 23. A peça tem forma de $\subset$ & M & $\square$ \\
\hline 24. A furadeira de peças é velha e obsoleta & M & $\square$ \\
\hline 25. 0 equipamento de solda do Sr. G. está quebrado há 5 meses & M & $\square$ \\
\hline 26. A furadeira de peças foi consertada no mesmo dia & MT & $\square$ \\
\hline 27. O contramestre manda o Sr. G. furar peças & MT & ○ \\
\hline 28. Eventualmente usa-se furadeira de chapas para furar peças & MT & ○ \\
\hline 29. A empresa muda trabalhadores de função & MT & $\square$ \\
\hline 30. 0 número de encomendas da empresa aumenta & MT & $\square$ \\
\hline 31. O efetivo da empresa está reduzido & MT & $\square$ \\
\hline 32. Há reativação da atividade econômica & MT & $\square$ \\
\hline 33. A empresa demite trabalhadores & MT & $\square$ \\
\hline 34. O número de encomendas da empresa diminui & MT & $\square$ \\
\hline 35. A empresa monta estruturas a partir de encomendas & MT & $\square$ \\
\hline 36. Há diminuição da atividade econômica & MT & $\square$ \\
\hline
\end{tabular}

O: variação; $\square$ :fato habitual; I: indivíduo; T: tarefa; M : material; M T: meio de trabalho.

vidas quanto à classificação. Um dos fatos listados na Tabela 2, o de número 26 , não participou do acidente e não está inscrito na árvore.

Em relação ao componente da atividade, os fatos distribuíram-se em ordem decrescente: tarefa - 11 fatos (31,4\%); meio de trabalho - dez fatos (28,6\%); material - nove fatos $(25,7 \%)$ e indivíduo - cinco fatos (14,3\%). Diferentemente do caso número 1, nesse acidente observase um certo equilíbrio na distribuição dos fatos entre os diferentes componentes da atividade.
A leitura e interpretação da árvore (Figura 3) revela que:

- o componente indivíduo, excluída a lesão, contribui com quatro fatos ou fatores de acidente, dos quais dois referem-se à situação do trabalhador em relação à ocupação - ser soldador e estar exercendo função de serralheiro. $\mathrm{O}$ terceiro refere-se ao seu desconhecimento dos riscos de furar peças com furadeira de chapas e o quarto, ao seu desconhecimento quanto à situação de uso da furadeira de peças, já consertada; 


\section{Figura 3}

Árvore de causas - caso no 2 .

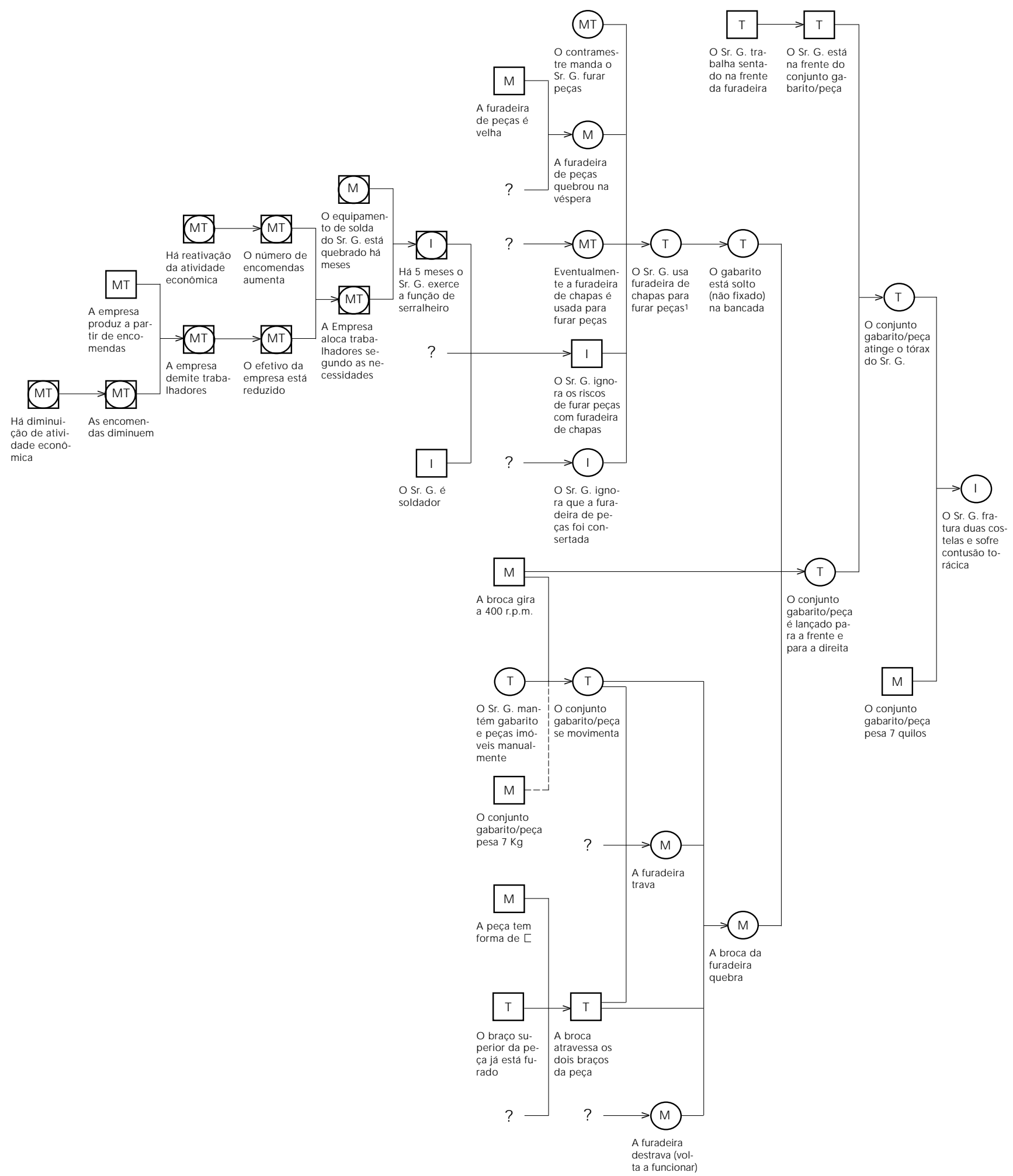

1 A furadeira de chapas não possui mecanismo de fixação. I: indivíduo; T: tarefa; M: material; MT: meio de trabalho. 


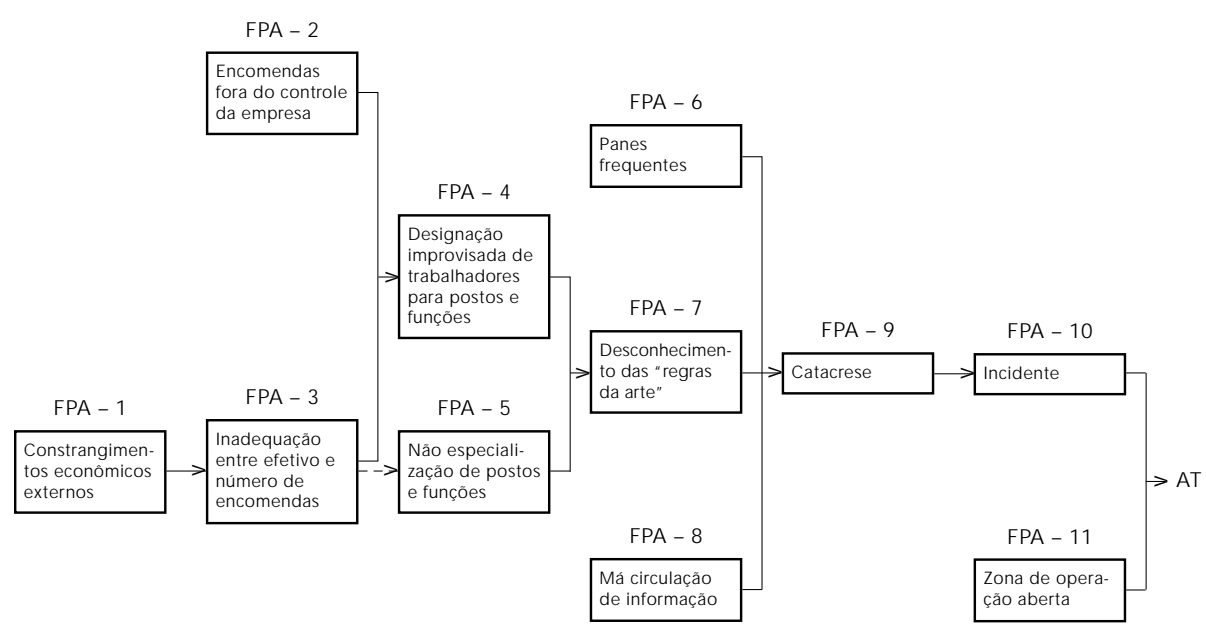

- há uma distribuição equilibrada entre os componentes tarefa, meio de trabalho e material;

- na origem do acidente, à esquerda da árvore, observa-se nítida predominância de fatores classificados como pertencentes aos componentes meio de trabalho e material.

A análise do esquema de fatores potenciais de acidentes (Figura 4) revela que, na origem remota do acidente, há participação de fatores gerenciais importantes. Submetida a constrangimentos econômicos externos (FPA - 1) e produzindo a partir de encomendas, cujo volume escapa de seu controle (FPA - 2), a empresa adota a prática de alocar trabalhadores de forma improvisada para funções e postos de trabalho (FPA - 4), com o objetivo de resolver os problemas decorrentes de efetivo insuficiente em relação às necessidades da produção (FPA - 4), prática que fragiliza a fiabilidade e a segurança do sistema. A tais fatores sobrepõe-se a decisão de manter em operação equipamentos velhos e obsoletos, sujeitos a panes (FPA - 6) e facilitadores da ocorrência de incidentes (FPA 10), o que acarreta a utilização de equipamentos impróprios à execução de determinadas tarefas (FPA - 9) ou catacrese, segundo denominação do autor que o descreveu (Faverge, 1977), compondo uma tríade conhecida de fatores potenciais de acidentes, aos quais somam-se falhas na circulação de informações (FPA - 8).

Esse caso revela ainda a existência de equipamento com zona de operação aberta (broca da furadeira desprotegida), condição identificável por meio de inspeção.
Estão inscritas na árvore (Figura 3) sete interrogações, apontando para lacunas de informação, merecendo destaque: a) Por que um equipamento para furar chapas é, ainda que eventualmente, utilizado para furação de peças? b) Por que um trabalhador que há cinco meses está desviado de função não recebeu treinamento que o capacitasse à execução de suas novas tarefas? c) Por que uma indústria de grande porte mantém em funcionamento um equipamento velho e obsoleto, sujeito a sucessivas panes, quando o preço de um novo é irrisório em face do porte da empresa?

Ao evidenciar a pluricausalidade e complexidade dos acidentes do trabalho, como pode ser constatado pelos dois casos apresentados, a aplicação do Método ADC dificulta culpar as vítimas, atribuindo-Ihes comportamento imprudente, negligente, descuidado - como freqüentemente ocorre em investigações realizadas por cipas de empresas (Binder et al., 1994).

Esses casos ilustram ainda algumas potencialidades do Método ADC e da aplicação do conceito de Fator Potencial de Acidentes, tais como:

- evidenciar fal has gerenciais e da organização do trabalho de uma empresa, potencialmente desencadeadoras de acidentes, com base no estudo detal hado de apenas dois casos; - pela revelação de elevado número de fatores implicados na ocorrência dos acidentes, contribuir para a superação da concepção dicotômica e pauci-causal desses fenômenos; - aumentar o conhecimento do trabalho e de seus riscos - papel pedagógico do método; 
- facilitar o diálogo entre diferentes interlocutores, na medida em que apenas fatores passíveis de constatação são inseridos nas árvores, que, pela facilidade de compreensão, constituem verdadeiros instrumentos de comunicação.

Cabe repetir que a indicação do Método de Árvore de Causas depende do nível de segurança já atingido pela empresa. Em situações de falta de segurança de máquinas e de inadequações evidentes de postos de trabal ho, a inspeção é o método mais indicado para identificação de riscos de acidentes do trabalho com vistas à prevenção (Monteau \& Favaro, 1990a e b; Monteau, 1992).

Os dois casos apresentados permitem inferir a existência de duas importantes exigências do método que não devem ser negligenciadas sob pena de deturpação de sua utilização, com comprometimento dos resultados obtidos: 1) necessidade de treinamento de seus aplicadores e 2) disponibilidade de tempo para sua aplicação.

Embora aparentemente de fácil aplicação, o método ADC requer disponibilidade de tempo, domínio da linguagem escrita e capacidade de elaboração de raciocínio lógico. Sua implantação em empresas francesas, iniciada em fins da década de 70 e ainda em curso, tem mostrado que há necessidade de treinamento e de reciclagens periódicas de seus aplicadores e, principalmente, que os resultados em termos de prevenção dependem do envolvimento da direção das empresas no processo (Pham, 1989).

Em investigações realizadas por profissionais integrantes de serviços externos às empresas, particularmente programas de saúde do trabalhador, a adoção de medidas de prevenção a partir da identificação de fatores de acidentes cuja eliminação não está prevista nas normas legais (MT, 1996) depende de decisão da empresa. Assim, o aproveitamento das potencialidades do método ADC em termos de prevenção fica condicionado à existência de canais de negociação envolvendo empregados, empregadores e profissionais de saúde e segurança.

Do exposto, cabe questionar as tentativas do Ministério do Trabalho de tornar obrigatória a utilização desse método para investigação de todo e qualquer acidente, em todas as empresas (MT, 1994a e b).

Finalmente, cabe lembrar que, enquanto manifestação de relações sociais historicamente determinadas, os acidentes do trabalho constituem problema cuja resolução situa-se no campo da luta política. Métodos de investigação, por mais aperfeiçoados e por mais bem aplicados que sejam, constituem ferramentas auxiliares e limitadas de prevenção e controle desses fenômenos.

\section{Referências}

ALVES, S. \& LUCHESI, G., 1992. Acidentes do trabalho e doenças profissionais no Brasil. A precariedade das informações. Informe Epidemiológico do SUS, 1:5-20.

BINDER, M. C. P.; MONTEAU, M. \& ALM EIDA, I. M., 1995. Árvore de Causas. Método de Investigação de Acidentes do Trabal ho. São Paulo: Publisher Brasil Editora.

BINDER, M. C. P.; AZEVEDO, N. D. \& ALMEIDA, I. M., 1994. A construção da culpa. São Paulo. Trabalho eSaúde, 14(37):15-17.

CUNY, X. \& KRAWSKY, G., 1970. Pratique de l'analyse d'accidents du travail dans la perspective sociotechnique de l'ergonomie des systhèmes. Le Travail Humain, 33:217-228.

DARMON, M.; MONTEAU, M.; QUINOT, E.; ROHR, D. \& SZEKELY, J., 1975. Les Facteurs Potentiels d'Accidents. Méthode et Instruments pour la Prévention des Risques Industriels. Paris: Institut National de Recherche et de Sécurité. Rapport n. 200.
FAVERGE, J. M., 1977. Analyse de la Sécurité du Travail en Termes de Facteurs Potentiels d'Accidents. Bruxelles: Université Libre de Bruxelles, Laboratoire de Psychologie Industriel. (mimeo.)

FERRÃO, G. M., 1996. Colhendo resultados. Proteção, 58:44-46.

HIRATA, H. S. \& SALERNO, M. S., 1995. L'implantation d'outils statistiques sur l'organisation et les conditions de travail dans les pays dits "semidéveloppés" - Le cas du Brésil. Cahier Travail et Emploi, (Supplément sur le Journée-Débat du 19 Janvier 1994: Usage des Méthodes Statistiques dans l'Étude du Travail):117-129.

IBGE (Instituto Brasileiro de Geografia e Estatística), 1981. Anuário Estatístico do Brasil. Brasília: IBGE.

IBGE (Instituto Brasileiro de Geografia e Estatística), 1982. Anuário Estatístico do Brasil. Brasília: IBGE.

IBGE (Instituto Brasileiro de Geografia e Estatística), 1983. Anuário Estatístico do Brasil. Brasília: IBGE. 
IBGE (Instituto Brasileiro de Geografia e Estatística), 1984. Anuário Estatístico do Brasil. Brasília: IBGE. IBGE (Instituto Brasileiro de Geografia e Estatística), 1985. Anuário Estatístico do Brasil. Brasília: IBGE.

IBGE (Instituto Brasileiro de Geografia e Estatística), 1986. Anuário Estatístico do Brasil. Brasília: IBGE.

IBGE (Instituto Brasileiro de Geografia e Estatística), 1987. Anuário Estatístico do Brasil. Brasília: IBGE.

IBGE (Instituto Brasileiro de Geografia e Estatística), 1988. Anuário Estatístico do Brasil. Brasília: IBGE.

IBGE (Instituto Brasileiro de Geografia e Estatística), 1989. Anuário Estatístico do Brasil. Brasília: IBGE.

IBGE (Instituto Brasileiro de Geografia e Estatística), 1990. Anuário Estatístico do Brasil. Brasília: IBGE.

INRS (Institut National de Recherche et de Sécurité), 1976. De l'accident aux actions de prévention. La notion de facteurs potentiels d'accidents. Travail et Sécurité, 554:1-11.

LARA DUCA, A. C., 1987. Estudo de causas de acidente pelo método INRS. $V$ Congresso da ANAMT. Florianópolis.

MAGRINI, R. O., 1989. Acidente fatal na GM : versão dos trabalhadores. Revista de Debates. Sindicato dos Metalúrgi cos de São José dos Campos, novembro:5-17.

MT (Ministério do Trabalho), 1994a. Portaria n. 5 de 18 de abril de 1994. Secretaria de Segurança e Saúde no Trabalho. Diário Oficial da União, 19 de abril:5.741-5.744.

MT (M inistério do Trabalho), 1994b. Portaria n. 968 de 09 de agosto de 1994. Secretaria de Segurança e Saúde no Trabalho. Diário Oficial da União, 11 de agosto, secção 1: 12.113.

MT (Ministério do Trabalho), 1996. Normas Regulamentadoras - NR do Capítulo V do Título II da Consolidação das Leis do Trabalho. São Paulo: Ed. Atlas (Portaria 3.214 de 08 de junho de 1978).
MONTEAU, M. \& PHAM , D., 1987. L'accident du travail: I'évolution des conceptions. In Traité de Psychologie du Travail (C. Leboyer \& J. C. Sperandio, eds.), pp 703-727, Paris: Presses Universitaires de France.

MONTEAU, M. \& FAVARO, M., 1990a. Bilan des méthodes d'analyse a priori des risques. Des contrôles à l'ergonomie des systhèmes. Cahiers de Notes Documentaires, 138:91-122.

MONTEAU, M. \& FAVARO, M., 1990b. Bilan des méthodes d'analyse a priori des risques. Principales méthodes de la sécurité des systhèmes. Cahiers de Notes Documentaires, 139:363-389.

MONTEAU, M., 1974. Essai de classement des risques professionnels et des actions de prévention. Cahiers de Notes Documentaires, 78:255-262.

MONTEAU, M., 1980. L'utilisation et la place de l'arbre des causes dans I'analyse des accidents du travail. Principes et aplication. Séminaire European sur la Securité des Systhèmes. Nancy, France. (mimeo.)

MONTEAU, M., 1983. Accident analysis. In: Encyclopaedia of Occupational Health and Safety (L. Parmeggiani, org.), pp. 13-16, Génève: International Labour Office.

MONTEAU, M., 1992. La gestion de la sécurité du travail dans l'entreprise: du carter au plan qualité. Performances Humaines \& Techniques, 61:29-34.

PHAM, D., 1989. Quelques facteurs de reussite ou d'échec de l'introduction dans l'entreprise de la méthode "Arbre des Causes" de l'INRS. Cahiers de Notes Documentaires, 135:347-354. 